\title{
A CASE OF THE ZOLLINGER-ELLISON SYNDROME WITH ASSOCIATED SPLENOMEGALY
}

\author{
W. R. O'FlynN, M.B., B.Ch., F.R.C.S. \\ Senior Surgical Registrar; Royal Marsden Hospital, London, S.W.3
}

\begin{abstract}
MaNY case reports of the Zollinger-Ellison syndrome have appeared since the original description in 1955 . The following case is considered worthy of reporting because unusual features made diagnosis difficult, and treatment hazardous.
\end{abstract}

\section{Case Report}

The patient (F. C., R.M.H. No. 038695), a male, aged 49, presented elsewhere with a duodenal ulcer of six months' duration, for which antecolic partial gastrectomy was performed on 23.6.58. Epigastric pain recurred within three months. Barium meal examination revealed an anastomotic ulcer, which was treated by excision of the ulcer with a further gastric resection, and again an antecolic anastomosis. His symptoms recurred after one month, and he was eventually referred to the Royal Marsden Hospital. Barium-meal examination then showed an anastomotic ulcer $3 \mathrm{~cm}$. in diameter in the jejunum $2 \mathrm{~cm}$. below the stoma. Night gastric secretion tests yielded $106 \mathrm{mEq}$. free $\mathrm{HCl}$ and $246 \mathrm{mEq}$. total acid; bile being present in quantity. He was admitted on 9.5.59 complaining of severe persistent epigastric pain, for which routine medical therapy was instituted without success.

Investigations: $\mathrm{Hb}$ 18.1g. (128\%), w.b.c. $15,300 /$ cu. mm., neutrophils $88.4 \%$, lymphocytes $6.4 \%$. There was no history of vomiting or abstaining from oral fluids to account for the high hæmoglobin reading and its further elucidation was not undertaken at this stage because it was considered that his severe epigastric pain and tenderness demanded urgent surgical intervention.

Operation: He was explored on Ir.5.59 when the presence of a large anastomotic ulcer was confirmed. This had penetrated the jejunum and become adherent to the parietal peritoneum of the anterior abdominal wall-the ulcer base being left on the peritoneum after mobilisation. The spleen was judged to be three times the normal size, extending to the left costal margin. No abnormality was detected in the pancreas. The ulcer was oversewn after mobilisation and a transhiatal vagotomy performed.

Progress: Post-operative progress was uneventful, with dramatic relief of his epigastric pain. At the time of his discharge from hospital on 17.7.59 he was symptom-free, and enjoying a normal diet.

Hamatological Investigations: These were instituted post-operatively, and are set out below:

24.6.59: Hb., 14.8g, (100\%), w.b.c.15,100/cu. mm., neutrophils $89.0 \%$, lymphocytes $5.0 \%$, PCV $45 \%$, r.b.c. 5,900,000/cu. mm., MCV 76 cu. $\mu$, MCH $25 \%$, MCHC 33\%, platelets 840,000/cu. mm. 29.6.59: Sternal marrow aspirate: 'Cellular particulate marrow aspirated easily. The marrow contains little fat and is evidently very active, without any obvious abnormality in any series of cells. $L: E$ ratio c. $2: 1$. Megakaryocytes $\vec{N}$ are conspicuous and rather large, but not excessive? in numbers. Basophil precursors are rather plentifulso This marrow is compatible with a disorder in the 3 polycythæmia vera-hæmorrhagic thrombocythæmia group.' Marrow section: 'Section confirms the hyper- 6 cellularity of the marrow, and shows that there is an excess of megakaryocytes.'

In view of these findings, and of the splenomegaly, it was considered that the diagnosis of polycythæmia $\infty$ vera was well established. $4.7 \mathrm{mc}$. of ${ }^{32} \mathrm{P}$ were admini-o stered on 1.7.59.

Progress: The patient did not attend again until $\vec{Z}$ 16.1.61. Nine months before (I I months after his vagotomy) he had noted an episode of severe diarrhœa $\overparen{\Phi}$ which had lasted for two months. It had then cleared $\exists$ for two months, after which it had recurred, and persisted until the time of his attendance. The bowes tended to open after meals; the stools were loose and $\vec{\bullet}$ offensive, and occasionally contained undigested foo. \& For four months the diarrhœa had been associat with severe lower abdominal pain which was colicksy in nature, but there had been no recurrence of his original epigastric pain. He was readmitted to the Royal Marsden Hospital.

On examination, he was obviously wasted, having lost $22 \mathrm{lb}$. in weight, and was having frequent bouts of $\unrhd$ severe colicky lower abdominal pain. General examination was negative. The abdomen was diffusely tender, 윽 with hyperactive bowel sounds. No splenomegaly was detected. Rectal examination revealed loose offensive stools.

Investigations: Hb. 13.3g. $(90 \%)$, w.b.c. $6,200 / \frac{\partial}{2}$ cu. mm., neutrophils $88.0 \%$, lymphocytes $10.0 \%$, platelets $337,000 / \mathrm{cu}$. mm., Serum proteins $6.4 \mathrm{~g} / 100 \mathrm{ml}$., albumin 3.9g., globulin 2.5g. Examination of stools: no excess of neutral fat. Night gastric secretion: 3 10 $\mathrm{mEq}$. free $\mathrm{HCl}, 828 \mathrm{mEq}$. total acid, much bile $O$ was present. Barium meal: there was a large ulcer situated anteriorly in the efferent loop of the jejunum 9 ust be low the anastomosis. A jejuno-colic fistula was present which arose at the site of the ulcer.

Operation: At further exploration on 23.2.61 the upper abdominal cavity was obliterated by dense $N$ adhesions. The jejuno-colic fistula was isolated and after separation of jejunum from colon, the defect $\mathbb{O}$ in the latter was closed. A further gastric resection $N$ was then undertaken, this being rendered most arduous $\omega$ by dense adhesions, by the spleen which was still estimated to be three times the normal size, and by grossly dilated veins in the gastro-splenic ligament, $\frac{}{\Phi}$ and about the cardia. It was remarked at the time that $\stackrel{\oplus}{?}$ these veins resembled the veins seen in this region in cases of portal hypertension. As dissection proceeded, $\frac{T}{0}$ a tumour $6.5 \mathrm{~cm}$. in diameter was noted in the splenic 


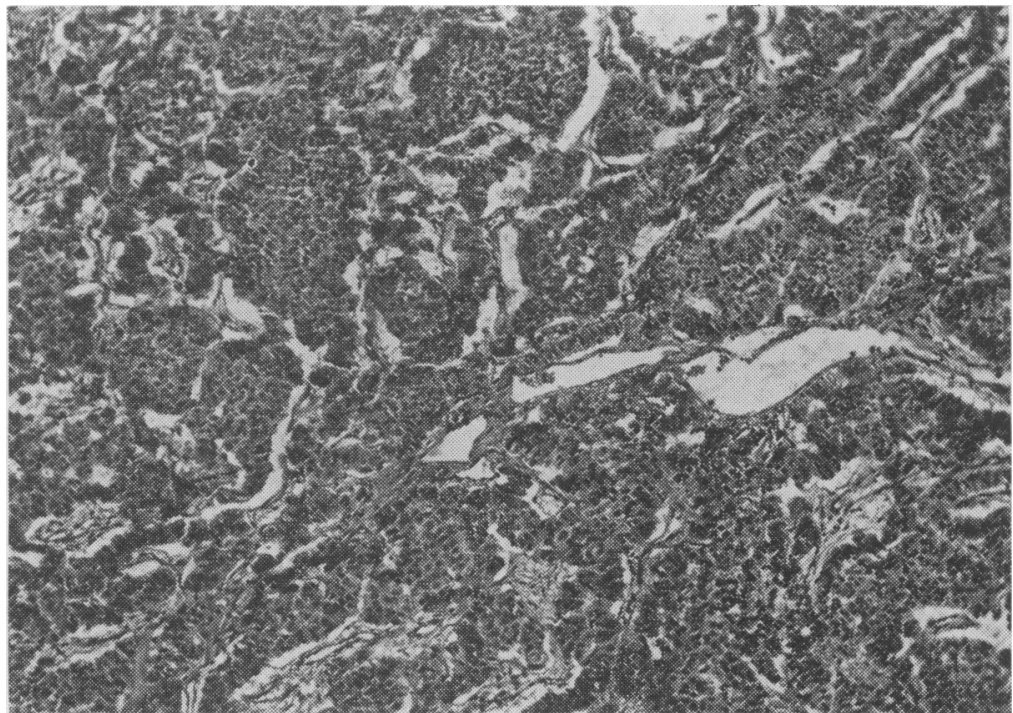

FIG. I.-Islet cell tumour showing characteristic endocrine arrangement. H.E. x 80 .

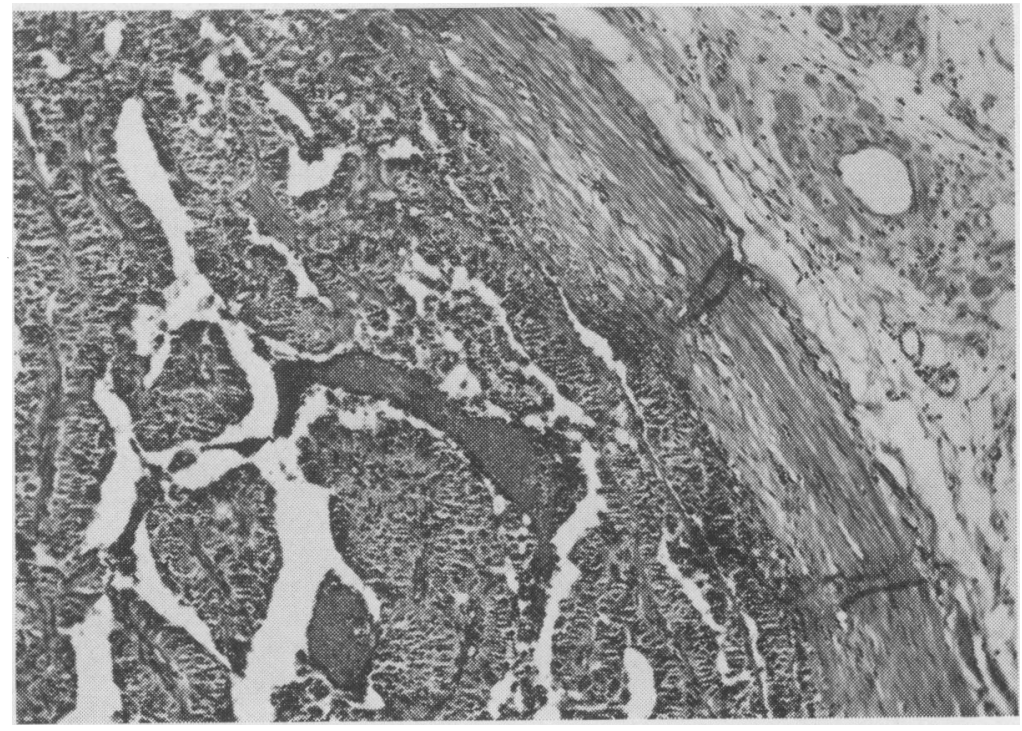

FIG. 2.-Islet cell tumour filling lumen of vein. H.E. $x 80$.

hilum, apparently arising from the tail of the pancreas. A sub-total gastrectomy with splenectomy and excision of the tail of the pancreas containing the tumour was performed.

The postoperative course was complicated by a severe wound infection, and by a bullous erythema multiforme with arthritis of the right wrist and of the left knee. Both conditions cleared satisfactorily before his discharge on 26.4.6r. He was then well, and without symptoms.

Pathological Report: Two specimens were received. I. Main surgical specimen comprising the spleen, $16.5 \times 12 \times 7.5 \mathrm{~cm}$., a tumour mass in the tail of the pancreas, and attached adipose tissue and lymph nodes. The tumour measures $6.5 \mathrm{~cm}$. in diameter. It is firm in consistency and the cut surface shows broad greyish bands of fibrous tissue separating softer, pinkish areas; it is not encapsulated. 2. A 'sleeve' of stomach wall 5 cm. long.
Histology The neoplasm (Fig. 1.) is a typical isletcell tumour composed of polyhedral, cuboidal and columnar cells arranged as masses and sinuous strands in a highly vascular stroma. In many fields the tumour cells come into intimate contact with the vessel wallsa characteristic 'endocrine' arrangement. The stroma varies greatly in amount and consistency; in some areas it is scanty whilst in other parts it is abundant and either œdematous or hyaline. There is some patchy necrosis. Staining with Gomori's aldehyde-fuchsin fails to reveal any definite $\beta$ granules: with Gomori's chrome-alum hæmatoxylin, phloxine-tartrazine technique many of the cells stain bright red, suggesting $\alpha$ cell differentiation. No argentaffin or argyrophil granules can be demonstrated. In the stroma at the periphery of the growth and in the adjacent lymph nodes there are a number of 'tuberculoid' granulomata, probably representing a reaction to tissue breakdown products. No metastases 


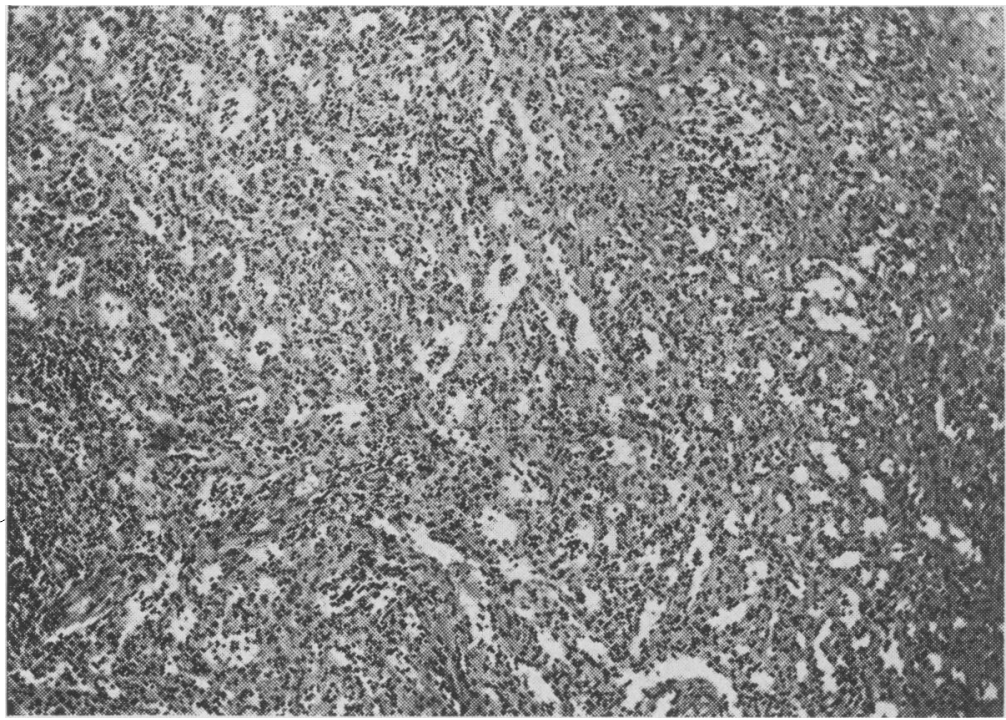

Fig. 3.-Spleen. Sinusoids dilatech and walls thickened. Note smalis Malpighian body near left lowe 5 border. H.E. x 80 .

are present in the nodes but invasion of a medium-sized vein is seen (Fig. 2). Diagnosis Islet-cell carcinoma.

The spleen (Fig. 3) shows thickening of the sinusoidal walls and increased prominence of the littoral cells; the Malpighian bodies are rather small and are widely separated. The appearances are not typical of polycythæmia but suggest a vascular 'back-pressure' effect, possibly due to pressure of the tumour on the splenic vein.

In one of the sections prepared from the portion of stomach, there is an area of active peptic ulceration with fibrosis extending through to the serosa. The adjacent mucosa is entirely of the fundal type, and displays prominent oxyntic and zymogenic cells. There is no evidence of neoplasia.

Gastrin-like activity: A portion of the tumour, fresh and unfixed, was deep-frozen, and submitted to Professor R. A. Gregory, but no trace of gastrin-like activity could be demonstrated in it (Gregory, Tracy, French and Sircus, 1960).

Progress: The patient was admitted for review on 2.3.63 (two years after excision of his tumour). There were no symptoms, he was eating a normal diet and his bowel function was normal.

Investigations: Night secretion test: no free or combined acid present. Examination of stools for occult blood: negative. Hb I5.9 g. (107\%), w.b.c. $27,200 /$ cu. mm. neutrophils $84.0 \%$, lymphocytes $10.5 \%$, monocytes $5.0 \%$. PCV $50 \%$, r.b.c. $5,340,000 /$ cu. mm., MCV 94 cu. $\mu$, MCH $30 \gamma \gamma$, MCHC $32 \%$, platelets 2,085,000/cu. mm.

The high platelet count was confirmed and ${ }^{32} \mathrm{P},(5 \mathrm{mc}$.) was administered to diminish the risk of thrombosis.

\section{Discussion}

This patient illustrates well the recurrence of ulcer symptoms, and the persistence of hyperacidity after routine gastric resection, which are features of the Zollinger-Ellison syndrome (Zollinger and Ellison, 1955).

At the time of his third exploration (the first operation undertaken at the Royal Marsden Hos- pital) the pancreas appeared normal on palpation, $\vec{z}$ the large fragile spleen and dense adhesions makingo exploration of the left upper quadrant very difficult. The splenomegaly together with the elevated hæmoglobin reading was considered, most probably, to be a manifestation of polycythæmia vera, $a$ condition in which approximately $15 \%$ of theo cases have peptic ulceration (Fitts, Eade, Peskin añ d Frost, 1960). The findings in the subsequent hæmatological investigation were compatible with this diagnosis and ${ }^{32} \mathrm{P}$ was given. At the moment he has a great excess of platelets without polycy-0 thæmia and the final hæmatological diagnosis is stilp obscure.

It is interesting to note that vagotomy relieved $\overrightarrow{\overrightarrow{0}}$ his pain. The jejuno-colic fistula occurred $\mathrm{I}^{\exists}$ months after vagotomy, and was presumably preceded by ulceration, but there was no complaint of recurrence of his epigastric pain. The pain, when ito did occur, was in the lower abdomen, was colicky in nature, and appeared to be due to his enteritis.

When he was explored for the fourth time, $20^{\circ}$ months after his vagotomy, the large spleen againo appeared, and the very large veins between the fundus of the stomach and the spleen, and about theo cardia, were a striking feature. No other evidence of portal hypertension was noted, and those partso of the liver which were seen appeared normal Liver function tests carried out after operations showed no abnormality. The tumour, which pre sented in the hilum of the spleen, arose from the extreme end of the tail of the pancreas, and was notw a tumour arising from aberrant pancreatic tissue. IE is presumed that it escaped detection previouslyo because of its inaccessible position, and smaller size

The splenomegaly was presumably caused by? venous congestion due to occlusion of the splenico vein. In the specimen invasion of a medium-sized $\overline{0}$ vein was noted (Fig. 2). 
Total gastrectomy has been advocated by Zollinger and Craig (1960a and b) in the treatment of these cases, whether or not a resectable pancreatic tumour is present. This procedure was not carried out in our case, because of the patient's poor general condition, the magnitude of the surgery already undertaken, and the presence of the great dilated veins in the fundal and hiatal regions. However, a radical subtotal gastrectomy was achieved. $\mathrm{He}$ has remained well for two years, having now a high platelet count but no evidence of polycythæmia. The tumour being malignant, it is feared that further ulceration may occur, as metastases develop. It is proposed to estimate the night acid secretion, and to test for fæcal occult blood at intervals, in an effort to anticipate further ulceration and its complications.

\section{Summary}

A case of the Zollinger-Ellison syndrome is described. A large non-beta-cell carcinoma arising in the tail of the pancreas apparently caused a 'back pressure' effect on the spleen. The resulting splenomegaly and venous engorgement made detection of the tumour difficult. The clinical problem was further complicated by an abnormal blood picture initially suggestive of polycythæmia vera.

I wish to thank Mr. R. C. B. Ledlie for permission to publish this case, and for his help and encouragement Dr. J. B. Harman and Mrs. E. M. Ledlie who managed the hæmatological aspects; Dr. N. F. C. Gowing for the histology studies; Dr. H. M. E. Kay for the extensive hæmatological investigations; Dr. J. J. Stevenson for the radiological investigations, and Professor R. A. Gregory, who examined the tumour for gastrin-like activity.

\title{
REFERENCES
}

Fitts, W. T., Erde, A., Peskin, G. W., and Frost, J. W. (i96o): Surgical Implications of Polycythæmia Vera, Ann. Surg., I52, 548.

Gregory, R. A., Tracy, H. J., French, I. M., and Sircus, W. (1960): Extraction of a Gastrin-like Substance from a Pancreatic Tumour in a Case of a Zollinger-Ellison Syndrome, Lancet, i, I045.

Loughridge, J. J., Neill, D. W., and Willis, J. (1960): Zollinger-Ellison Syndrome: Report of a Case, Brit. F. Surg., 48, 158 .

Rawson, A. B., England, M. T., Gillam, G. G., French, J. M., and Stammers, F. A. R. (1960): Zollinger-Ellison Syndrome with Diarrhæea and Malabsorption, Lancet, ii, 131.

Zollinger, R. M., and Craig, T. V. (I960): Ulcerogenic Tumour of the Pancreas, Amer. F. Surg., 99, 424.

(1960b): Endocrine Tumours and Peptic Ulcer, Amer. F. Med., 29, 76r.

- , and Ellison, E. H. (1955): Primary Peptic Ulcerations of the Jejunum Associated with Islet Cell Tumours of the Pancreas, Ann. Surg., 142, 709.

\section{FOLIC ACID DEFICIENCY IN HAEMOLYTIC ANAEMIA}

\author{
J. Forshaw, M.A., M.D.(Camb.), M.R.C.P. \\ Consultant Physician \\ Lilian HaRwood, F.I.M.L.T. \\ Senior Technician \\ Hamatology Laboratory, Sefton General Hospital, Liverpool, 15
}

Folic acid deficiency with a megaloblastic bone marrow picture may develop in both the acquired and hereditary types of hæmolytic anæmia (Chanarin, Dacie and Mollin, 1959). This is attributed to the demands of increased erythropoiesis, and it is particularly liable to occur when the dietary intake of folic acid is poor (MacIver and Went, 1960).

The purpose of the present paper is to describe a patient in whom an acute hæmolytic episode rapidly produced folic acid deficiency, and after spontaneous recovery of the hæmolysis the folic acid deficiency was almost completely corrected without treatment.

\section{Case Report}

A man, aged 34, was admitted to hospital in July 1962 , complaining of breathlessness on exertion, lassitude and intermittent lower abdominal pain for two weeks. He had never had any previous illnesses and he had not taken any drugs. There was no family history of anæmia. His diet had consisted mainly of corned beef, sausages, fish cakes, potatoes and bread, and he ate green vegetables very rarely.

On examination he was pale and the spleen was palpable $4 \mathrm{~cm}$. below the costal margin. His weight was 9 st. $2 \mathrm{lb}$.

Investigations: Hb. 7.8 g./100 ml., w.b.c. $1,450 /$ cu. mm. (polys $67 \%$, lymphs $29 \%$, monos $\mathrm{r} \%$, eosins $2 \%$, basophils $1 \%$ ), platelets $160,000 / \mathrm{cu}$. mm., reticulocytes $1 \%$. Examination of the stained blood film showed moderate anisocytosis and poikilocytosis. Bone marrow examination showed erythroid hyperplasia, numerous megaloblasts and a decrease in the polymorphs, the differential count being: blast cells $4 \%$, myelocytes and metamyelocytes $43 \%$, polymorphs and band cells $8 \%$, proerythroblasts $7 \%$, normoblasts $11 \%$, megaloblasts $24 \%$. $54 \%$ of the megaloblasts were in the basophilic stage.

The serum vitamin $B_{12}$ level was $140 \mu \mu \mathrm{g}$. $/ \mathrm{ml}$. (normal range $140-95 \circ \mu \mu \mathrm{g} / \mathrm{ml}$.). In the histidine loading test (Kohn, Mollin and Rosenbach, 1961) there was a large amount of FIGLU in the urine. Schumm's test was positive. The direct Coombs' test was positive to an anti-human globulin dilution of $1 / 64$. In the gamma-globulin neutralization test (Dacie, r95I) agglutination of the red cells was not inhibited by addition of gamma-globulin to the antiglobulin serum. Twenty-four autohæmolysis was increased to $4.6 \%$. No antibodies were demonstrated in the serum.

Virus complement fixation tests were negative three weeks and six weeks after admission. L.E. cells were 